\title{
A Culture of Safety
}

\author{
Charles N. Cornell
}

Received: 5 November 2017/Accepted: 8 November 2017/Published online: 18 December 2017

(C) Hospital for Special Surgery 2017

In response to the increasing frequency of adverse events documented during hospitalization, "culture of safety" programs have been developed and pursued by most US hospitals. The advent of the surgical checklist, the pre-op time out, and the TeamSTEPPS ${ }^{\circledR}$ approach have been documented to lower the frequency of adverse events following routine surgical procedures $[1,2]$. The aerospace industry has provided much of the theory and guidance for the development and application of these programs in surgery. The complex tasks required to pilot airplanes demand adoption of routines that improve communication and teamwork to reduce the chances of human error. Many experienced pilots and astronauts recognized the similarity of their teamwork approach to the execution of surgical procedures and have developed a training designed to help surgeons and hospital systems become safer.

In spite of nearly a decade since the American Academy of Orthopaedic Surgeons endorsed the adoption of these approaches, many high-quality orthopaedic programs continue to report adverse events. During the first weekend of November, I participated along with my hospital's leadership team in an intensive training in order to initiate this type of program at our hospital. Our goal is the complete elimination of adverse events in our institution.

For me, the training was inspirational. The concepts are simple and logical, but the barriers to incorporation of the principles into many traditional surgical cultures can be daunting. To be successful, surgical teams must develop open communication and be disciplined in using checklists and conducting briefings and debriefings before and after all surgical procedures. Respect and trust among team members

\footnotetext{
Electronic supplementary material The online version of this article (https://doi.org/10.1007/s11420-017-9595-z) contains supplementary material, which is available to authorized users.
}

C. N. Cornell, $(\bowtie)$

Hospital for Special Surgery,

535 East 70th Street,

New York, NY 10021, USA

e-mail: cornellc@hss.edu are mandatory. All team members must engage with confidence to ensure the avoidance of error and the success of procedures.

It seems so simple and obvious, but the culture within surgical institutions can be ridiculously hard to change. This training has inspired me to commit myself to complete ownership of the behaviors required to achieve complete patient safety. I will particularly welcome future manuscripts that describe the success or pitfalls associated with attempts to incorporate such guidelines into practice.

Volume 14 Issue 1 of HSS Journal ${ }^{\circledR}$ has a number of articles addressing reconstructive surgery of the upper extremity that should appeal to readers with that subspecialty interest. I hope the entire table of contents will impress you. This issue is notable for a diverse but very timely selection of papers.

\section{Compliance with Ethical Standards}

Conflict of Interest: Charles N. Cornell, MD, has declared that he has no conflict of interest.

Human/Animal Rights: This article does not contain any studies with human or animal subjects performed by the author.

Informed Consent: N/A

Required Author Forms Disclosure forms provided by the author are available with the online version of this article.

\section{References}

1. Khanula HS, Nasser ZA, Jones FC, Ficke JR, Burney III DW. Implementation of TeamSTEPPS in orthopaedic surgery. Instr Course Lect. 2017;66:635-645.

2. Gawande A. The checklist manifesto: how to get things right. New York: Henry Holt and Co.; 2010. 